\title{
Plantain Peels Powder, Burnt Palm Head Powder and Commercial Sodium Hydroxide as Additives for Water Based Drilling Mud
}

\author{
PERETOMODE, JP \\ Department of Petroleum and Gas Engineering, Delta State University, Abraka, P. M. B. 22, Oleh Campus, Nigeria. \\ E-mail: peretomodejeffery7@gmail.com Tel: +2348035831365, +234809243661
}

\begin{abstract}
Drilling operation efficiency is enhanced by the application of drilling mud constituted with suitable additives. This work investigates the use of locally sourced plantain peels powder (PPP) and burnt palm head sponge powder (BPHSP) in comparison with the use of commercial sodium hydroxide $(\mathrm{NaOH})$ as additives for the enhancement of the $\mathrm{pH}$ and rheological properties of water-based mud. The water-based mud samples with and without various amounts $(1.0-5.0 \mathrm{~g})$ of PPP, BPHSP and commercial $\mathrm{NaOH}$, respectively. Analyses of the results revealed that the $\mathrm{pH}$ and rheological properties (apparent viscosity, plastic viscosity and yield point) of the formulated waterbased mud were relatively enhanced with the respective use of the commercial $\mathrm{NaOH}$, BPHSP and PPP as additives. The $\mathrm{pH}$, apparent viscosity and yield point respectively increased with increase in the quantity of each of the added additives (commercial $\mathrm{NaOH}, \mathrm{BPHSP}$ and PPP). The commercial $\mathrm{NaOH}$ had the highest percentage of improvement on the mud pH with $22.2-50 \%$, followed by that of BPHSP $(16.7-44.4 \%)$ and PPP $(11.1-33.3 \%)$, respectively. Therefore, commercial sodium hydroxide, burnt palm head sponge ash powder and plantain peels powder can respectively be used as additives to enhance or improve the $\mathrm{pH}$ and rheological properties (viscosity and yield point) of water-based mud.
\end{abstract}

\section{DOI: https://dx.doi.org/10.4314/jasem.v22i7.1}

Copyright: Copyright $\odot 2018$ Peretomode. This is an open access article distributed under the Creative Commons Attribution License (CCL), which permits unrestricted use, distribution, and reproduction in any medium, provided the original work is properly cited.

Dates: Received: 09 April 2018; Revised: 30 May: 2018; Accepted: 11 June 2018

Key words:Drilling mud; pH; Plantain peels; Palm head sponge; Rheological properties.

Drilling fluids (mud) are complex mixtures of interacting components and their properties markedly change during drilling, with change in temperature and pressure, time, solid contents, rate of penetrationand formation zone been drilled (Okorie, 2009). It is significant to understand the changes in drilling fluid properties in order to eliminate any drilling problem which may arise. Numerous studies have been conducted to effectively understand change in fluid properties under downhole conditions (Okorie, 2009). Drilling fluid enhances drilling by transporting the cuttings to the surface thereby sufficiently cleaning the wellbore.During drilling operations, diagnostic mud test are carried out on the drilling fluid to control the mud density, rheology/flow properties, filtration, solid content, viscosity, $\mathrm{pH}$ and so on in order to properly maintain the set values and also to avoid drilling problems. It has been shown that the presence of dissolved gases such as $\mathrm{O}_{2}, \mathrm{CO}_{2}$ and $\mathrm{H}_{2} \mathrm{~S}$ in drilling mud promote corrosion problems and adversely affects the reliability of downholeequipment (Pal, 2011).

Drilling fluids perform better in a $\mathrm{pH}$ range between 8.0 and 10.5 for water-base mud. If the $\mathrm{pH}$ of the mud is low below 7.0, it becomes acidic and can corrode equipment and also pollute the environment (Okorie, 2009). Imported chemicals such as soda ash $\left(\mathrm{Na}_{2} \mathrm{CO}_{3}\right)$ caustic soda $(\mathrm{NaOH})$ and calcium hydroxide $(\mathrm{Ca}$ $\left.\left(\mathrm{OH}_{2}\right)\right)$ are usually added to the mud to raise the $\mathrm{pH}$ to 8.0 or 10.5. When drilling across formations the presence of contaminants such as salts (chloride) water calcium carbonates and sulfides will affect the properties of the drilling mud which is noticeable in the rheological properties of the mud (Pal, 2011). These contaminants will drastically thicken or thin the mud, causing separation of bentonite or treatment polymer in the mixing tank or in the hole. Most of these contaminants come from the mud water makeup. When this becomes the case there is need to control, modify or treat the mud in terms of $\mathrm{pH}$ with a $\mathrm{pH}$ additive. Therefore, the objective of this study is to investigate the use of locally sourced plantain peels powder and burnt palm head sponge powder in comparison with commercial standard sodium hydroxide as $\mathrm{pH}$ and rheological properties enhancing additives for water-based drilling mud.

\section{MATERIALS AND METHOD}

Materials: Nigerian Bentonite clay, Palm Head Sponge obtained from palm tree plantation located in 
Irri, Delta State, Nigeria, is used as a source of local sodium hydroxide. Plantain peel which is used as source of both local sodium hydroxide and potassium hydroxide was obtained from roadside roasted plantain sales women in Ughelli, Delta State, Nigeria. All other chemicals and reagents $\left(\mathrm{Na}_{2} \mathrm{O}\right.$ and $\left.\mathrm{NaOH}\right)$ used in this study are of analytical grade.

Sample preparation: The palm head sponge was shredded to remove palm seeds and dirt. It was then sun-dried for two weeks, oven-dried at $70^{\circ} \mathrm{C}$ for $1 \mathrm{~h}$ and then burnt into ash. The burnt palm head sponge ash powder was then collected, sieved (200micron sieve size) and packaged prior to use. The unripe plantain peels were properly washed with doubledistilled water to remove dirt and debris. The washed peels were sliced into smaller sizes, sun-dried for two weeks and then oven-dried at $70^{\circ} \mathrm{C}$ for $1 \mathrm{hr}$. The peels were pulverized into powder and thereafter sieved and packaged prior to use.

Preparation of water-based mud and beneficiation: The water-based drilling mud with an initial $\mathrm{pH}$ of 9.0 was prepared according to the standard of American Petroleum Institute (API, 2000). Bentonite clay $(21.0 \mathrm{~g})$ was weighed (using a triple beam weighing balance) into the mixer cup of a spindle multi-mixer equipment. Then, $1.0 \mathrm{~g}$ of commercial sodium hydroxide $(\mathrm{NaOH})$ was added, followed with the addition of $350 \mathrm{ml}$ of double-distilled water (with $\mathrm{pH}$ of 7).

The spindle multi-mixer is connected to an A.C. power source. The powered multi-mixer was switched on and the contents in the mixer cup (being held in a fixed position) was allowed to thoroughly and homogeneously mixed together for duration of $1 \mathrm{hr}$. This procedure was repeated for 2.0 to $5.0 \mathrm{~g}$ of commercial $\mathrm{NaOH}, 1.0-5.0 \mathrm{~g}$ of burnt palm-head sponge ash powder (BPHSP) and $1.0-5.0 \mathrm{~g}$ of plantain peels powder (PPP), respectively. The mud density was measured using a Baroid mud balance. The plastic viscosity and yield point of the formulated mud was evaluated. The $\mathrm{pH}$ of the formulated mud was measured using a 1 -inch universal $\mathrm{pH}$ paper indicator. All the experiments were carried out in triplicate and the average value of each parameters determined was used.

Determination of drilling mud $\mathrm{pH}$ : The $\mathrm{pH}$ of the drilling mud with and without the addition of commercial and local additives was determined using the 1-inch universal $\mathrm{pH}$ paper strip or indicator. The 1inch $\mathrm{pH}$ paper indicator was inserted into the mud samples and left for about few seconds to $1 \mathrm{~min}$. The color change of the $\mathrm{pH}$ paper strip after it has absorbed sufficient fluid was matched with reference chart colors provided. The $\mathrm{pH}$ values of the color indicated by the mud sample in turn was read and recorded as the $\mathrm{pH}$ of the mud samples being tested.

Determination of mud viscosity and yield point: The viscosity of the drilling mud was determined using Fann V G Rheometer equipment. The prepared waterbased mud was poured into a container and subjected to shear in the rheometer at a rotation speed of 600 and $300 \mathrm{rpm}$, respectively. At each rotation speed, the dial reading was taken at the time when the rotation speed was steady or stabilized. The plastic viscosity (PV) of the formulated water-based mud was calculated using Eq. (1):

$$
P V=\theta_{600 r p m}-\theta_{300 r p m} \mathrm{~s}
$$

Where $(\theta)$ is the dial readings at $600 \mathrm{rpm}$ and $300 \mathrm{rpm}$, respectively. The $\mathrm{PV}$ is in centipoise.

The apparent viscosity (APV) was estimated using Eq. (2):

$$
A P V=\frac{\theta_{600 r p m}}{2}
$$

The yield point (YP) of the formulated water-based mud which is inlb per 100sqftwas estimated using Eq. (3):

$$
Y P=\theta_{300 r p m}-P V
$$

\section{RESULTS AND DISCUSSION}

The rheometer dial readings at 600 and $300 \mathrm{rpm}$ and the estimated plastic viscosity, apparent viscosity, yield point and mud density values for the formulated water-based mud with and without the addition of commercial $\mathrm{NaOH}$, BPHSP (as source of $\mathrm{NaOH}$ ) and PPP (as source of $\mathrm{NaOH}$ and $\mathrm{KOH}$ ) are presented in Table 1.As presented in Table 1, it is seen that the mud weight of the formulated water-based mud with and without additives is $8.6 \mathrm{Ib} / \mathrm{gal}$ and this value remained the same irrespective of the amount of different additives that was added in the formulation. This observation indicated that the addition of the additives had no effect on the density of the formulated waterbased mud. Table 1 shows that the PV range of $4-6$ $\mathrm{cP}, 5-5 \mathrm{cP}$, and $3-4 \mathrm{cP}$; APV range of $6.5-12.5 \mathrm{cP}$, $6.5-11 \mathrm{cP}$ and $6-9 \mathrm{cP}$; YP range of $5-17,3-12$ and $4-12$ was each obtained when $1.0-5.0 \mathrm{~g}$ of commercial $\mathrm{NaOH}, \mathrm{BPHSP}$ and PPP was respectively added to the bentonite mud. PV of $3 \mathrm{cP}, \mathrm{APV} 4 \mathrm{cP}$ and YP, 2 was respectively obtained for bentonite mud without the addition of the respective additives. 
Table 1. The dial readings and the estimated values of the rheological parameters for the formulated water-based mud with and without additives

\begin{tabular}{ll|l|l|l|l|l|l}
\hline \multirow{2}{*}{$\begin{array}{l}\text { Additive Sample } \\
\text { Amount (g) }\end{array}$} & \multicolumn{2}{l|}{$\begin{array}{c}\text { Dial Readings } \\
\text { rpm }\end{array}$} & \multicolumn{3}{l}{ Rheological Properties } \\
\cline { 3 - 9 } & & $\mathbf{6 0}$ & $\mathbf{3 0 0}$ & PV & APV & YP & D \\
& & $\mathbf{0}$ & & & & & \\
\hline Bentonite mud (No additives) & - & 8 & 5 & 3 & 4 & 2 & 8.6 \\
\hline Bentonite mud with NaOH & 1 & 13 & 9 & 4 & 6.5 & 5 & 8.6 \\
& 2 & 19 & 13 & 6 & 8.5 & 7 & 8.6 \\
& 3 & 22 & 17 & 5 & 11 & 12 & 8.6 \\
& 4 & 24 & 20 & 4 & 12 & 16 & 8.6 \\
& 5 & 25 & 21 & 4 & 12.5 & 17 & 8.6 \\
\hline Bentonite mud with BPHSP & 1 & 13 & 8 & 5 & 6.5 & 3 & 8.6 \\
& 2 & 14 & 9 & 5 & 7 & 4 & 8.6 \\
& 3 & 17 & 12 & 5 & 8.5 & 7 & 8.6 \\
& 4 & 19 & 14 & 5 & 9.5 & 9 & 8.6 \\
& 5 & 22 & 17 & 5 & 11 & 12 & 8.6 \\
\hline Bentonite mud with PPP & 1 & 12 & 8 & 4 & 6 & 4 & 8.6 \\
& 2 & 13 & 10 & 3 & 6.5 & 7 & 8.6 \\
& 3 & 14 & 11 & 3 & 7 & 8 & 8.6 \\
& 4 & 16 & 13 & 3 & 8 & 10 & 8.6 \\
& 5 & 18 & 15 & 3 & 9 & 12 & 8.6 \\
\hline
\end{tabular}

It could be observed from Table 1 that the addition of 1.0 to $5.0 \mathrm{~g}$ of each commercial $\mathrm{NaOH}$ and BPHSP as well as $1.0 \mathrm{~g}$ of PPP to the bentonite mud resulted in a relative increase in the PV of the formulated waterbased mud as compared to the value obtained for the bentonite mud without the addition of the additives. Furthermore, the addition of 1.0 to $5.0 \mathrm{~g}$ of each of the additive (commercial $\mathrm{NaOH}$, BPHSP and PPP) to the bentonite mud led to an increased APV and YP of the formulated water-based mud when compared to the values obtained without the addition of these respective additives.More also, for each of the additives added to the bentonite mud, the APV and YP increased with increase in the quantity of the additives. In comparing the performance of the locally sourced biodegradable additives (BPHSP and PPP) with the commercial $\mathrm{NaOH}$ in relation to the PV, APV and YP, it could be seen that the performance of both BPHSP and PPP was relatively comparable with that of the commercial $\mathrm{NaOH}$.

The $\mathrm{pH}$ profile of the formulated water-based mud with and without the addition of commercial $\mathrm{NaOH}$, BPHSP (as source of $\mathrm{NaOH}$ ) and PPP (as source of $\mathrm{NaOH}$ and $\mathrm{KOH}$ ) as additives is as shown in Fig. 1.As shown in Fig. 1, it could be observed that the $\mathrm{pH}$ of the formulated water-based mud was increased from $\mathrm{pH} 9$ to a $\mathrm{pH}$ range of $11-13.5, \mathrm{pH}$ range of $10.5-13$ and $\mathrm{pH}$ range of $10-12$ when 1.0 to $5.0 \mathrm{~g}$ of commercial $\mathrm{NaOH}, \mathrm{BPHSP}$ and PPP was respectively added to the bentonite mud. It is also seen that the $\mathrm{pH}$ of the formulated water-based mud relatively increased with increase in the amount of each of the added additives (commercial $\mathrm{NaOH}$, BPHSP and PPP).Thus, the commercial $\mathrm{NaOH}$ had the highest percentage (or degree) of improvement on the mud $\mathrm{pH}$ with 22.2
$50 \%$ and this was followed by that of BPHSP with $16.7-44.4 \%$ and PPP with $11.1-33.3 \%$, respectively.

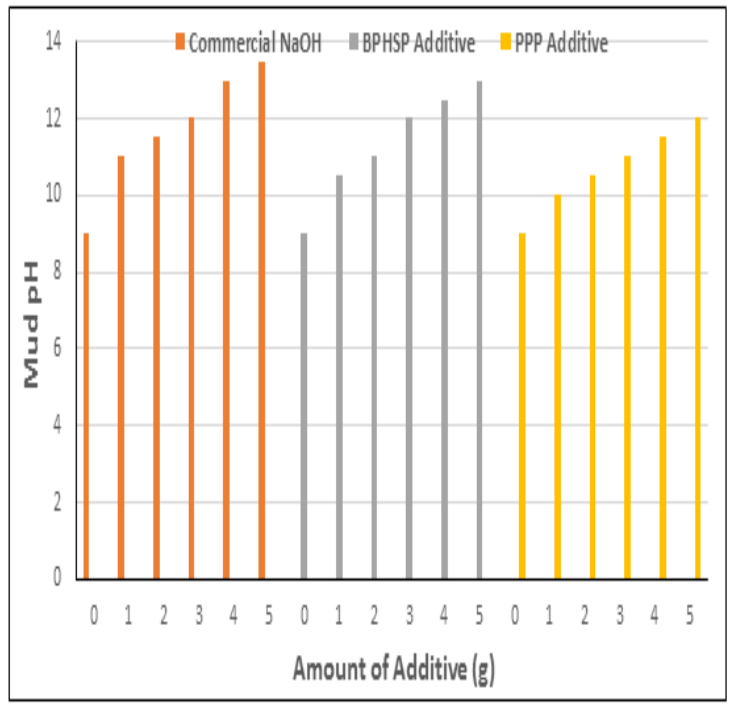

Fig. 1. Plot of formulated water-based mud $\mathrm{pH}$ as a function of the quantity of additives

Nevertheless, in comparing the degree of $\mathrm{pH}$ improvement achieved by the locally sourced biodegradable BPHSP and PPP with that of the commercial $\mathrm{NaOH}$, it could be seen that the respective performance ofBPHSP and PPP was relatively comparable with the commercial standard $\mathrm{NaOH}$.This observation affirms that both BPHSP and PPP can be used as $\mathrm{pH}$ enhancing additives or agents in the formulation of water-based muds.

Conclusion: Palm trees and plantains are crops which are frequently produced in quantities that exceed either export or local demand, it is readily available and accessible with its cost comparatively lower than cost 
required in acquiring commercial sodium hydroxide $(\mathrm{NaOH})$. From the result analysis, commercial sodium hydroxide, burnt palm head sponge ash powder and plantain peels powder can be used as additives to improve the rheological properties (viscosity and yield point) of water-based mud. These locally sourced materials are biodegradable and can be used as $\mathrm{pH}$ enhancing additives of water-based mud and subsequently serve as good alternatives to commercial $\mathrm{pH}$ enhancing additives like sodium hydroxide which will be of benefit to the oil and gas industries as it will reduce the cost of producing water-based drilling mud.

\section{REFERENCES}

Babatunde, GM (1992). Availability of banana and plantain products for animal feeding. In Machin, D; Nyvold, S (eds). Roots, Tubers, Plantains and Bananas in Animal Feeding. FAO Animal Production and Health Paper 95, FAO, Rome.

John McDermott, Park Ridge, Noyes, NJ (1973).Drilling mud and fluid additives (Chemical technology Review). Published by Park, N.J., Noyes Data Corp

Ibarra, L; Posadas, P; Esteban-Martinez, M (2004). Influence of some additives on rheological properties, viscosity and dynamic mechanical properties in NR compounds. J. Appl. Polymer Sci. 94(1): 332-344.

Rogovina, LZ; Vasil'ev, VG; Matveenko, VN; Churochkina, NA; Pryakhina, TA; Khokhlov, AR (2007). Rheological properties of solutions and gels of combined systems hydrophobically modified polyacrylamides-new viscoelastic cationic surfactants. J. Polymer Sci. Series A. 49(12):2173-2181
Okorie, OM (2009).Modification of Drilling Fluid pH with local Nigerian additives. Petrol. Technol. Develop. J. 1: 1595-9104

Ajasin, FO; Oluokun, JA; Obi, OO; Omole, AJ (2008). Performance Characteristics of Weaned Rabbit Fed Plantain Peel as Replacement for Maize. J. Nutr. Food. 38(6):559-563.

Pall, S (2011). Exercises within drilling fluid Engineering. Pall Skalle and Ventures publishing ApS.

Onwuachi-Iheagwara, PN (2015). Comparative analysis of the use of banana peels and $\mathrm{NaOH}$ in $\mathrm{pH}$ control in Nigerian clays. J. Nig. Assoc. Math. Phys. 30(1):197 - 202

Darley, HCH; George Gray R; Ryen Caenn (2011). Composition and Properties of Drilling and Completion Fluids. Gulf Professional Publishing.

Sabina, ZS; Alex, LY; Leong Yeow, V; David, B (2009).Obtaining the steady shear rheological properties and apparent wall slip velocity data of a water-in-oil emulsion from gap-dependent parallel plate viscometry data. Rheol Acta 48:221-229 